\title{
KATA BERFREKUENSI TINGGI DALAM PEMBELAJARAN BIPA PEMULA
}

High Frequency Words in Indonesian as Foreign Language at Beginers Level

\author{
Esra Nelvi Siagian
}

Badan Pengembangan dan Pembinaan Bahasa

esranelvi@yahoo.co.id

\begin{abstract}
Abstrak
Kosakata memegang peranan penting dalam pembelajaran bahasa asing, tetapi pengajar sering bingung menentukan kosakata apa saja yang harus diajarkan atau dijadikan target agar pemelajar dapat berkomunikasi dengan baik sesuai dengan tingkatannya. Penelitian ini bertujuan menghasilkan daftar kosakata yang paling sering digunakan, High Frequency Words-HFW, pada pembelajaran BIPA pemula. Hasil penelitian ini akan sangat bermanfaat bagi para pemelajar, pengajar, penulis, dan pengamat BIPA, serta pihak-pihak yang berkaitan dengan kebipaan. Pemanfaatan HFW dalam pembelajaran bahasa asing terbukti memberi efek positif, seperti meningkatkan motivasi belajar, meningkatkan rasa percaya diri untuk memproduksi kalimat sendiri, membantu memahami teks, dan pemanfaatan kata berulang-ulang akan membuat kosakata tersebut familiar bagi pemelajar. Penelitian kualitatif ini menggunakan korpus data buku-buku BIPA untuk level pemula dengan berbasis Standar Kompetensi Lulusan BIPA level satu dan dua sesuai Permendikbud Nomor 27 Tahun 2017 kemudian diolah menggunakan aplikasi AntCont. Hasil penelitian menunjukkan bahwa 1) HFW bahasa Indonesia untuk pemelajar BIPA berbeda dengan HFW bahasa Indonesia secara umum; 2) bentuk kelas kata yang diajarkan bervariasi; dan 3) bentuk imbuhan yang digunakan terbatas.
\end{abstract}

Kata-kata kunci: kata, berfrekuensi tinggi, BIPA pemula

\begin{abstract}
Vocabulary plays an important role in foreign language learning, but teachers are often confused about what vocabulary should be taught or targeted so that learners can communicate well according to their level. This study aims to produce a list of the most frequently used vocabulary, knows as High Frequency Words-HFW, in Beginner Indonesian as Foreign Language (ILF) level. The results of this research will be great used for IFL students, teachers, writers, and observers, as well as parties related to IFL. The use of HFW in foreign language learning is proven to have positive effects, such as increasing learning motivation, increasing self-confidence to produce one's own sentences, helping to understand texts, and using repeated words that will make the vocabulary familiar to learners. This qualitative research used corpus of BIPA books for the beginner level based on the level one and two IFL Competency Standards according to the regulation of education ministry Number 27 of 2017 then processed using the AntCont application. The results showed that 1) HFW for IFL is different from Indonesian HFW in general; 2) the form of word classes taught varies; and 3) limited of affix used.
\end{abstract}

Keywords: words, high frequency, beginner level of ILF

How to Cite: Siagian, Esra Nelvi. (2020). Kata Berfrekuensi Tinggi dalam Pembelajaran BIPA Pemula. Ranah: Jurnal Kajian Bahasa. 9(2). 188-201. doi: https://doi.org/10.26499/rnh.v9i2.2320 


\section{PENDAHULUAN}

Kosakata memiliki peranan penting dalam pembelajaran bahasa kedua atau bahasa asing. Agar bahasa asing yang dipelajari dapat diaplikasikan dalam kehidupan sehari-hari, pemelajar harus menguasai kosakata dalam konteks komunikasi yang akan dilakoni. Pemahaman kosakata dibutuhkan dalam merespons makna atau dalam mengungkapkan sesuatu. Oleh karena itu, kosakata merupakan modal penting untuk menguasai keterampilan membaca, mendengarkan, menulis, dan berbicara.

Dalam pembelajaran bahasa, penguasaan kosakata yang semakin kaya akan semakin menunjang keterampilan berbahasa. Pembelajaran bahasa perlu mempertimbangkan kosakata apa yang harus digunakan dalam pembelajaran tersebut, sesuai dengan konteks atau tema pembelajaran, high frequency words (HFW), academic words, dan technical words, bergantung pada level dan tujuan pembelajaran. Akan tetapi, sering sekali baik pemelajar maupun pengajar mengabaikan target kosakata apa yang akan dipelajari dan wajib dikuasai.

Berdasarkan beberapa hasil penelitian tentang peranan kosatakata dalam pembelajaran bahasa asing menunjukkan bahwa pemanfaatan kosakata berfrekuensi tinggi (HFW) berperan penting dalam menentukan keberhasilan pembelajaran bahasa asing. Menurut Serrano dan Garcia, hasil tes menunjukkan bahwa kosakata dengan tingkat kemunculan 10 kali, lebih diingat dari kata yang muncul 5 kali (Sánchez Gutiérrez, Serrano, \& García, 2019). Bahkan kosakata yang ditandai dengan huruf tebal untuk membantu pengenalan kata tidak memberi efek. Pemelajar lebih mengenal HFW dan merasakan manfaat dari kata tersebut (Dang, Webb, \& Averil Cohead, 2019). Sama dengan pembelajaran ESP, konten pembelajaran yang terintegrasi dan penggunaan terminologi yang berindeks tinggi akan lebih efektif, menghemat waktu belajar, dan mempermudah pemelajar bahasa (Jendrych, 2013). Bandingkan dengan siswa yang belajar bahasa Inggris selama 7 tahun di Saudia, menggunakan 13 buku teks hanya menguasai 1000 kata saja. Hal ini terjadi karena metode pengajaran kosakata yang nonincremental (tidak berulang), kosakata yang dipelajari tidak dapat dipertahankan dalam pikiran. Altyari merekomendasikan penggunaan 5000 kata yang paling sering digunakan dalam bacaan dan kurikulum (Altyari, 2017).

Penelitian lain yang menyatakan bahwa HFW berperan penting dalam pembelajaran bahasa dapat dilihat pada pemanfaatan kamus HFW dalam pembelajaran bahasa Perancis, memaksimalkan peningkatan kosakata pemelajar (German, 2009). Penggunaan HFW dalam 
pengajaran bahasa sangat penting, merupakan strategi mengajar dengan cara langsung dan merupakan metode repetisi (Johns \& Wilke, 2018). Belajar banyak kosakata dengan daftar panjang, tetapi jarang digunakan agaknya kurang efektif jika dibandingkan dengan belajar kosakata inti yang dapat dikombinasikan, sehingga membuat pemelajar menjadi komunikator yang efektif (Tao, 2009). HFW diyakini penting, menunjang keberhasilan pembelajaran bahasa asing karena mempelajari kata-kata yang penting yang meningkatkan motivasi dan percaya diri pemelajar dalam memroduksi kalimat sendiri. Semakin tinggi motivasi belajar, semakin baik hasil yang diperoleh (Maharani, 2019). HFW dapat membantu pemelajar mengetahui kategorisasi gramatikal awal sementara ucapan masih dipelajari (Frost, Monaghan, \& Christiansen, 2019). Hasil rekaman EEG juga menunjukkan ada perbedaan ketika pemelajar membaca kalimat yang berisi HFW dan LFW, pada penelitian mahasiswa yang kesulitan membaca (Sereno, Hand, Shahid, Mackenzie, \& Leuthold, 2020).

Berdasarkan penelitian-penelitian tersebut, dapat disimpulkan bahwa HFW memberi banyak manfaat dalam pembelajaran bahasa asing. Kamus HFW untuk pembelajaran bahasa asing dapat dengan mudah ditemukan, seperti kamus HFW bahasa Perancis, Jepang, dan Mandarin. Kamus merupakan alat penting dalam pembelajaran bahasa asing (Purwiyanti, Suwandi, \& Andayani, 2017). Pemanfaatan HFW menyebabkan kosakata bertahan lama dalam ingatan karena pengulangan-pengulangan dalam pembelajaran. HFW terbukti mempermudah dan meningkatkan percaya diri peserta didik dalam memroduksi kalimat. Dengan kata lain, pemanfaat HFW bermanfaat dan efektif serta menghemat waktu peserta didik dalam menguasai pembelajaran bahasa.

Penelitian tentang HFW bahasa Indonesia belum banyak dilakukan. Pertama, Frekuensi Kosakata Bahasa Indonesia, penelitian yang menghasilkan 3.800 kosakata dasar yang frekuensi penggunaannya 20 kali atau lebih (Muhadjir, dkk., 1996). Sumber data diperoleh dari surat kabar Kompas pada tahun 1994 dari 52 hari penerbitan yang diambil secara acak, sekali dalam seminggu. Kedua, Frequency-Based Indonesian Word List, sebuah penelitian hibah dari SEAMEO QITEP in Language pada tahun 2011 (Hananto, dkk., 2011) dengan korpus buku-buku sekolah SMP, cerita fiksi anak-anak dan dewasa, serta artikel pada koran. Ketiga, 50 kata berfrekuensi tinggi yang dapat diakses dari situs Leipzig, Corpora and Language Statistic (web-Leipzig, 2020) dengan korpus-wikipedia dan web Indonesia.

Penelitian ini akan fokus pada HFW yang muncul dalam pembelajaran BIPA pemula, (1\&2), level dengan jumlah pemelajar yang paling tinggi. Penelitian ini sangat penting karena HFW untuk kebutuhan pembelajaran BIPA belum pernah dilakukan. Selain itu, hasil 
penelitian ini akan memberi manfaat bagi pemelajar, pengajar, penulis bahan ajar, perancang evaluasi pembelajaran, dan pihak-pihak yang berkenaan dengan kebipaan.

\section{LANDASAN TEORI}

Kata, satuan bahasa yang dapat berdiri sendiri, berperan sangat penting dalam pembelajaran bahasa kedua, khususnya di awal pembelajaran. Penelitian tentang bagaimana memperoleh kosakata yang banyak agar dapat berkomunikasi dengan baik dan sempurna banyak dilakukan. Seorang penutur bahasa Inggris dewasa yang berpendidikan diyakini mengetahui setidaknya 20.000 kata, tetapi untuk kebutuhan percakapan sehari-hari, jumlah kata yang dibutuhkan hanya sekitar 2.000 kata. Demikian juga dalam bahasa Jepang dan Mandarin yang memiliki puluhan ribu karakter, kata yang biasa digunakan hanya sekitar 2.000 karakter saja (Lightbown \& Spada, 2011).

Salah satu faktor yang membuat kosakata baru mudah dipelajari adalah frekuensi kata tersebut dilihat, didengar, dan dipahami. Pemaknaan kata dapat dilakukan melalui melihat, mendengar, dan kebiasaan sehari-hari (Ramadan \& Yeti Mulyati, 2020). Paul Nation (2001) mengulas tentang sejumlah studi tentang pemelajar bahasa kedua perlu memiliki pertemuan yang bermakna dengan sebuah kata baru sebelum kata tersebut mapan dalam ingatannya. Kata tersebut kemudian akan dengan mudah diproduksi dalam konteks yang baru ketika berbicara dan secara otomatis atau fasih diucapkan atau ditulis karena telah dipahami. HFW, bermakna, dan kontekstual akan mudah dikuasai dan merupakan kata yang produktif dalam kehidupan sehari-hari.

Beberapa strategi yang digunakan dalam memperluas penguasaan kosakata adalah strategi word-building, cognates, menggunakan konteks, dan membaca secara intensif. Selain itu ada strategi memori, strategi yang membutuhkan pengulangan sebagai teknik menghafal. Pengulangan intensif membuat pembelajaran lebih cepat tentu saja dengan mengaitkannya dengan sesuatu yang telah diketahui sebelumnya. Ketika satu bagian sudah ada dalam memori, akan lebih mudah menggabungkannya dengan informasi kedua.

Penyimpanan memori berperan penting dalam hal mengingat, belajar, dan menciptakan sesuatu. Jenis penyimpanan memori umum ada dua, penyimpanan jangka pendek, Short Term Storage dan penyimpanan jangka panjang, Long Term Storage. Memori jangka pendek adalah tempat informasi yang terbaru dari peristiwa terbaru dan data sensorik seperti suara-peristiwa selama periode dari 30 detik hingga beberapa hari (Bhinnety, 2015). Kemampuan otak untuk menyimpan terbatas, informasi baru yang masuk akan mengeluarkan informasi sebelumnya. 
Sementara itu, ingatan jangka panjang memiliki kapasitas yang jauh lebih besar dan berisi hal seperti fakta, ingatan pribadi, atau nama-nama orang yang mungkin harus diingat.

Mayza, Andre (2020, Juli 1), seorang dokter spesialis saraf, ahli neurologi RSCM dalam sebuah wawancara personal menjelaskan bahwa jenis memori ada 3, yaitu memori pengalaman (hanya penyimpan pengalaman yang berharga), konseptual (menyimpan konsep dan fakta), dan kata (berkaitan dengan konsep wujud bunyi). Proses memori dibentuk melalui tiga tahapan, yaitu input, proses, dan output. Pada tahap input, pesan baik dalam lisan maupun tulisan diterima melalui indra penglihatan dan pendengaran. Masukan tersebut kemudian diproses, hanya bagian intisari atau bagian yang bermakna yang diambil untuk dipahami, bukan semua kata yang didengar atau dibaca. Tahapan penyimpanan dimulai dari proses penyimpanan informasi di memori jangka pendek, kemudian informasi yang dianggap memang perlu akan dikirim ke memori jangka panjang (tidak hanya menyimpan makna saja, tetapi juga menyimpan hafalan verbatim atau pernyataan ulang yang disampaikan kata demi kata secara tepat). Pada tahap output, dua tahapan yang digunakan adalah recognisi dan recall. Seseorang diminta merekognisi sesutu yang telah diberikan padanya melalui jawaban dari pertanyaan yang diajukan. Pada tahap recall, menyebutkan kembali suatu kata yang dilihat dan didengar sebelumnya.

SKL BIPA adalah pedoman yang dipakai dalam pembelajaran BIPA, seperti, merumuskan kurikulum, menentukan bahan pembelajaran, merencanakan dan melaksanakan pembelajaran, dan menentukan lulusan peserta didik. Penyusunan SKL diadaptasi dari Common European Framework of Reference for Language (CEFR) dengan menggunakan penjenjangan dalam Uji Kemahiran Berbahasa Indonesia (UKBI), alat uji yang telah digunakan untuk menguji kemahiran berbahasa Indonesia bagi orang Indonesia maupun orang asing, sedangkan CEFR merupakan kerangka acuan pembelajaran bahasa asing di Eropa yang dianggap relevan sebagai rujukan penentuan kompetensi setiap level dalam bidang bahasa.

Tabel 1.

Penjenjangan pada CEFR, SKL BIPA, dan UKBI

\begin{tabular}{lll}
\hline \multicolumn{1}{c}{ CEFR } & \multicolumn{1}{c}{ SKL BIPA } & \multicolumn{1}{c}{ UKBI } \\
\hline A1: Breakthrough & Bipa 1 (Pemula) & Terbatas \\
\hline A2: Waystage & Bipa 2 (Pemula) & Marginal \\
\hline B1: Threshold & Bipa 3 (Madya) & Semenjana \\
\hline B2: Vantage & Bipa 4 (Madya) & Madya \\
\hline $\begin{array}{l}\text { C1: Effective Operational } \\
\text { Proficiency }\end{array}$ & Bipa 5 (Mahir) & Unggul \\
\hline C2: Mastery & & \\
& Bipa 6 (Mahir) & Sangat Unggul \\
\cline { 2 - 3 } & Bipa 7 (Mahir) & Istimewa \\
\hline
\end{tabular}


Kemampuan berbahasa pada level A1 dan BIPA 1 dianggap masih sangat terbatas. Pelafalan masih diucapkan dengan sangat hati-hati, berbicara masih sangat lambat, dan kosakata yang dikuasai terbatas pada kata-kata yang sederhana dan sangat familiar. Selanjutnya pada level A2 dan BIPA 2, kemampuan berbahasa masih sederhana dan terbatas pada area diri sendiri, seperti data diri, keluarga, dan pekerjaan. Pelafalan sudah lebih jelas walaupun ketika berbicara masih lambat.

Kompetensi pemelajar BIPA 1 yang harus dicapai pada akhir pembelajaran adalah dapat memahami dan menggunakan ungkapan konteks perkenalan diri dan pemenuhan kebutuhan konkret sehari-hari dan rutin dengan cara sederhana untuk berkomunikasi dengan mitra tutur yang sangat kooperatif, sedangan pemelajar BIPA 2 dapat mengungkapkan perasaan secara sederhana, mendeskripsikan lingkungan sekitar, dan mengomunikasikan kebutuhan seharihari dan rutin. Adapun pengetahuan kebahasaan yang harus dikuasai level BIPA 1 adalah penggunaan tata bahasa dan kosakata dalam berbagai jenis teks yang diajarkan yang meliputi, penggunaan bunyi bahasa dan pelafalan; kata ganti orang; struktur frasa benda (DM); kata bilangan tingkat; kata negasi; kalimat sederhana; kata tanya; kata ganti tunjuk; kata kerja ada; posisi dan lokasi; kata depan; kata kerja berimbuhan; kata keterangan; kata hubung; ungkapan dan kata sapaan; dan kata yang berhubungan dengan topik umum, sedangkan pada level 2, pemelajar dapat menguasai penggunaan tata bahasa dan kosakata dalam berbagai jenis teks yang diajarkan yang meliputi, penggunaan kata negasi, kata tanya, kata sifat, kata ulang, perbandingan, penggunaan jenis-jenis kalimat, penggunaan kata hubung, kata depan, dan kata keterangan, penggunaan imbuhan, kata penggolong, kata seru, dan penggunaan kosakata yang berhubungan dengan topik tertentu.

\section{METODE PENELITIAN}

Korpus data yang digunakan untuk penelitian ini adalah buku pada tingkat pemula sebanyak 17 buku. Data dianggap valid karena telah mewakili buku level pemula yang ditulis oleh penulis buku BIPA dari lembaga kursus, universitas, perorangan, dan penerbit, baik yang tidak dan diperjualbelikan di dalam negeri maupun di luar negeri (Jepang, Australia, dan Thailand), juga telah mewakili pemerintah dan pihak swasta. Selain itu, data yang digunakan dari buku-buku tersebut dipilih hanya bagian materi yang sesuai dengan level pemula berdasarkan acuan SKL.

Pengumpulan data dilakukan dengan tahapan berikut. Pertama, mengumpulkan bukubuku BIPA yang ada di Indonesia dan di luar negeri baik dalam bentuk cetak maupun digital. 
Kedua, memilah data (materi dalam bentuk percakapan) yang sesuai dengan tema yang ada pada level pemula sesuai dengan SKL BIPA dan dilanjutkan dengan mengetik ulang data dalam bentuk word. Data yang digunakan untuk penelitian ini hanya data berupa percakapan. Langkah selanjutnya adalah mengolah data dengan menggunakan aplikasi AntCont agar diperoleh daftar kata dengan frekuensi kemunculan tertinggi hingga terendah. Kemudian dilakukan pemilahan kosakata yang dianggap tidak perlu seperti nama orang, makanan, minuman, dan merek, serta kosakata asing. Langkah terakhir adalah menganalisis data.

Aplikasi AntCont diciptakan oleh Lawrence Anthony pada tahun 2006. Aplikasi ini dapat diperoleh dengan gratis dengan cara mengunduh. Cara menggunakannya, yaitu data yang akan dianalisis (fail txt) diunduh dengan menggunakan aplikasi notepad. Hasil yang diperoleh berupa daftar kata-kata, jumlah kata, dan frekuensi kemunculan pada teks. Kosakata akan diurutkan mulai dari peringkat tertinggi atau kata yang paling sering digunakan pada teks.

Untuk mendapatkan HFW yang sesuai dengan ejaan yang berlaku dan kaidah bahasa Indonesia, dilakukan pengolahan data secara manual.

1. Mengeliminasi data berupa nama orang, kata asing, angka, dan kata yang tidak memiliki arti.

2. Mengubah huruf kapital menjadi huruf bukan kapital pada awal kata.

3. Memisahkan kata-kata yang tidak sesuai dengan Kamus Besar Bahasa Indonesia, edisi kelima 2018 (KBBI, 2018).

4. Memisahkan kosakata yang memiliki bentuk lah, kah, pun, $k u, m u$, dan per (bukan awalan), kecuali kata adapun, ataupun, meskipun, sekalipun, sungguhpun, dan walaupun.

5. Mengelompokkan kata yang secara morfologis memiliki bentuk dasar yang sama.

Analisis data dilakukan untuk menghasilkan HFW yang dapat digunakan dalam bahan ajar BIPA tingkat pemula. Untuk kebutuhan pengajaran dapat dilakukan penelitian lanjutan.

\section{PEMBAHASAN}

Melalui pengolahan data sesuai tahapan di atas akhirnya diperoleh jumlah kosakata sebanyak 3.695. Kata-kata yang sesuai dengan KBBI berjumlah 1.202, kata asing sebanyak 46 kata, bentuk kata ulang sebanyak 8, kata seru berjumlah 9, kata-kata yang tidak dikenal tidak ada, dan sejumlah kata cakapan. Kata-kata lain yang unik adalah kata-kata yang salah 
eja, nama diri, nama organisasi, kota, tempat, buah, makanan, bunga, binatang, produk, dan singkatan atau akronim.

Aplikasi AntCont secara otomatis memisahkan setiap satuan kata berdasarkan penanda spasi. Aplikasi tidak mengenal frasa atau kata majemuk juga kata ulang walaupun menggunakan tanda hubung “-“", sehingga kata terima kasih dipisah dan dihitung dua kata, yaitu terima dan kasih. Demikian pula dengan kata ulang, seperti kata kura-kura, laki-laki, kadang-kadang, gado-gado, abu-abu, dan ngomong-ngomong dipisah menjadi kata kura, kadang, gado, abu, dan ngomong masing-masing dihitung sebanyak dua kali. Selain itu, ditemukan juga bahwa ternyata beberapa penulis bahan ajar masih melakukan kesalahan dalam penulisan preposisi di dan ke, seperti, dirumah, disebelah, disekolah, disini, kearah, dan kekantor. Paling banyak terjadi pada penulisan preposisi di dan ke dan kata kerja pasif $d i$-.

\section{Kata Berfrekuensi Tinggi}

Hasil penelitian ini dengan dua penelitian sebelumnya berbeda. Berikut sepuluh HFW dari hasil penelitian yang dilakukan pada tahun 1996, 2011, dan 2020.

Tabel 2

Sepuluh Kata dengan Tingkat Penggunaan Tertinggi

\begin{tabular}{|c|c|c|}
\hline I & II & III \\
\hline $\begin{array}{l}\text { Fekuensi Kosakata Bahasa } \\
\text { Indonesia }\end{array}$ & $\begin{array}{l}\text { Frequency-Based Indonesia } \\
\text { Word Lists }\end{array}$ & HFW Pembelajaran BIPA \\
\hline 1996 & 2011 & 2020 \\
\hline 1. Yang & 1. yang & 1. saya \\
\hline 2. Dan & 2. dan & 2. $\mathrm{di}$ \\
\hline 3. $\mathrm{Di}$ & 3. di & 3. уа \\
\hline 4. Itu & 4. dengan & 4. dan \\
\hline 5. Dengan & 5. itu & 5. Anda \\
\hline 6. Ini & 6. ini & 6. ini \\
\hline 7. Dari & 7. dari & 7. apa \\
\hline 8. Dalam & 8. tidak & 8. ada \\
\hline 9. Untuk & 9. untuk & 9. $\mathrm{ke}$ \\
\hline 10. Tidak & 10. dalam & 10. selamat \\
\hline
\end{tabular}

Kolom I dan II menunjukkan HFW sama, yaitu kata yang, dan, di, itu, dengan, ini, dari, dalam, untuk, dan tidak. Perbedaannya ada pada peringkat kata-kata tersebut, seperti pada kata dengan dan itu, serta kata dalam, untuk dan tidak. Bandingkan dengan kolom III, kata yang sama dengan kolom I dan II hanya ada tiga kata, yaitu kata di, dan, dan ini. Sedangkan 7 kata lainnya, seperti kata saya, ya, Anda, apa, ada, ke, dan selamat tidak muncul pada penelitian sebelumnya.

Perbedaan tersebut terjadi karena sumber data yang digunakan berbeda. Jika kolom II menggunakan korpus buku-buku pelajaran tingkat dasar, novel dewasa, dan koran online; 
kolom I menggunakan korpus koran Kompas, sedangkan kolom III menggunakan korpus buku-buku pembelajara BIPA tingkat pemula dengan berbasis SKL BIPA. Dengan demikian, topik-topik sumber data juga berbeda. Pada buku-buku BIPA pemula, topik percakapan merupakan percakapan sehari-hari yang sangat sederhana. Korpus berisi tentang bagaimana mengomunikasikan informasi tentang diri sendiri, kebutuhan sehari-hari, dan aktivitas rutin kepada mitra tutur. Dengan demikian, kata saya dan Anda merupakan kata yang tingkat kemunculannya sangat tinggi sehingga wajib untuk dikuasai. Begitu juga dengan kata tanya $a p a$, (dibutuhkan sebagai alat untuk bertanya akan sesuatu hal); kata ya, (kata dasar yang memiliki banyak fungsi seperti menjawab panggilan, menyatakan setuju, atau membenarkan); dan kata selamat (merupakan kata yang sangat awal dikenal ketika belajar BIPA). Kata selamat, hampir setiap hari diucapkan untuk menyapa atau memberi salam kepada orangorang yang ditemui, seperti selamat pagi, siang, sore, dan malam. Untuk fungsi sosial lainnya, seperti selamat jalan, datang, tahun baru, lebaran, dan natal. Untuk level yang lebih tinggi digunakan untuk menyatakan ucapan, doa, dan pernyataan terbebas dari bahaya.

Tabel 3

Kosakata Berfrekuensi Tinggi

\begin{tabular}{ll}
\hline Keterangan & \multicolumn{1}{c}{ Kata } \\
\hline Pronomina & $\begin{array}{l}\text { saya (778), aku (141), Anda (265), kamu (174), dia (75), kita (64), kalian (29), } \\
\text { dan mereka }(13) .\end{array}$ \\
\hline Kata Sapaan & Bu (64), Pak (34), Mas (6), Bang (2) dan Dik (2). \\
\hline Kata Tanya & $\begin{array}{l}\text { apa (245), berapa (140), apakah (74), bagaimana (33), mana (129), dan siapa } \\
\text { (70), dimana (16), dan } \text { kemana (9). }\end{array}$ \\
\hline Preposisi & $\begin{array}{l}\text { Kata preposisi yang paling sering digunakan adalah kata di (489), ke (197), } \\
\text { dan dari. }\end{array}$ \\
\hline
\end{tabular}

HFW pronomina sangat tinggi, saya (778), aku (141), Anda (265), kamu (174), dia (75), kita (64), kalian (29), dan mereka (13). Dengan demikian, kata ganti orang merupakan kosakata wajib yang harus dikuasai dalam pembelajaran awal BIPA, sedangkan kata sapaan atau panggilan yang paling sering digunakan adalah Bu (64), Pak (34), Mas (6), Bang (2) dan Dik (2). Tahapan pertama yang diajarkan adalah pronomina persona pertama dan kedua karena pada tahap awal target pembelajaran adalah mampu menggunakan ungkapan konteks perkenalan diri dan berkomunikasi dengan mitra tutur secara sederhana.

Kata tanya yang paling sering muncul adalah kata tanya apa sebanyak 245 dan apakah sebanyak 74. Walaupun kata tanya pertama yang diajarkan adalah kata siapa dalam konteks menanyakan nama, kata apa merupakan kata tanya yang sangat penting untuk dikuasai. Pengajar juga perlu menjelaskan pemakaian bahasa baku, dengan posisi kata tanya di awal kalimat juga penambahan bentuk partikel -kah. Kata tanya lain yang cukup banyak adalah 
berapa (44), apakah (34), bagaimana (33), mana (24), dan siapa (19). Selain itu, kata tanya mana untuk menanyakan tempat dengan variasi di, ke dan dari juga cukup tinggi. Akan tetapi, kemunculan kata di mana dan ke mana tidak dapat dimunculkan karena aplikasi secara otomatis memisahkannya. Namun, kata dimana (16) dan kemana (9), dengan penulisan secara tata bahasa bahasa Indonesia kurang tepat, terbilang cukup tinggi (PUEBI, 2015). Hal ini menunjukkan materi ajar BIPA mengandung kesalahan dalam penulisan preposisi $d i$ dan $k e$. Penulis bahan ajar belum dapat membedakan di sebagai kata depan atau sebagai kata kerja pasif.

Berikut adalah $50 \mathrm{HFW}$ yang diperoleh setelah dilakukan penggolahan berupa penghapusan nama diri, bahasa asing, singkatan dan kesalahan penulisan.

Tabel 4

Lima Puluh kata Tertinggi

\begin{tabular}{lllllllll}
\hline 1 & 778 & saya & 18 & 142 & bisa & 35 & 95 & sekali \\
2 & 489 & di & 19 & 141 & aku & 36 & 94 & bapak \\
3 & 326 & ya & 20 & 140 & berapa & 37 & 93 & hari \\
4 & 276 & dan & 21 & 139 & itu & 38 & 92 & akan \\
5 & 265 & anda & 22 & 139 & sama & 39 & 88 & saja \\
6 & 252 & ini & 23 & 132 & pak & 40 & 88 & sampai \\
7 & 245 & apa & 24 & 129 & mana & 41 & 84 & makan \\
8 & 223 & ada & 25 & 124 & dengan & 42 & 84 & tinggal \\
9 & 197 & ke & 26 & 119 & baik & 43 & 82 & jam \\
10 & 189 & selamat & 27 & 112 & ibu & 44 & 82 & petugas \\
11 & 181 & kasih & 28 & 106 & bu & 45 & 81 & pelayan \\
12 & 180 & terima & 29 & 106 & untuk & 46 & 78 & pagi \\
13 & 178 & dari & 30 & 104 & nama & 47 & 75 & dia \\
14 & 177 & kamu & 31 & 103 & juga & 48 & 74 & apakah \\
15 & 176 & tidak & 32 & 98 & kalau & 49 & 74 & lagi \\
16 & 169 & mau & 33 & 98 & sudah & 50 & 74 & orang \\
17 & 150 & yang & 34 & 96 & rumah & & & \\
\hline
\end{tabular}

Daftar HFW tersebut disarankan menjadi kosakata wajib yang dikuasai di awal pembelajaran. Hal tersebut diyakini akan memotivasi pemelajar dan memberi rasa percaya diri dalam berkomunikasi atau memproduksi kalimat-kalimat sendiri.

\section{Kelas Kata}

Berikut adalah lima daftar kata yang paling sering digunakan yang disusun berdasarkan kelas kata nomina, verba, adjektiva, adverbial, pronominal, partikel, numerilia, dan klitika.

Tabel 5

Kosakata Berdasarkan Kelas Kata

\begin{tabular}{llllllll}
\hline Nomina & Verba & Adjektiva & Adverbial & Pron. & Partikel & Num. & Klitika \\
& & & & & & & \\
\hline terima kasih & Ada & baik & tidak & saya & di & dua & -nya \\
nama & bisa & selamat & mau & apa & ya & satu & - mu \\
pak (cak) & makan & sama & juga & Anda & dan & tiga & $-k u$ \\
\hline
\end{tabular}




\begin{tabular}{lllllll}
\hline rumah & sampai & suka & sudah & ini & ke & lima \\
ibu & tinggal & senang & sekali & mana & dari & tujuh \\
\hline
\end{tabular}

Daftar kata di atas berdasarkan SKL BIPA masuk dalam kompetensi capaian pembelajaran BIPA 1 dan 2.

\section{Interjeksi/Kata Seru}

Tabel 6

Interjeksi

\begin{tabular}{ll}
\hline Keterangan & \multicolumn{1}{c}{ kata } \\
\hline Kata Seru & menyatakan kagum, wah (21), waduh (menyatakan heran, kagum, terkejut), \\
& syukurlah (menyatakan lega dan senang), asyik (senang), eh (heran dan \\
& kaget), dan aduh (heran dan sakit) masing-masing 2 kali, serta kata ayo, oh, oh \\
& ya, sih, wow, yuk, yah, halo
\end{tabular}

Interjeksi atau sering disebut kata seru adalah kata-kata yang digunakan untuk mengungkapkan perasaan karena kaget, marah, rindu, kagum, terharu, dan sedih. Seruan dapat dilakukan dengan kata yang singkat seperti wah, ha, sih dan dengan bentuk kata biasa seperti aduh, gila, celaka, alhamdulilah, dan astaga. Seperti data di atas, dapat dilihat bahwa kata seru yang mendominasi adalah kata seru yang singkat yaitu, wah (21) untuk menyatakan kagum, kemudian diikuti kata seruan bentuk biasa, seperti kata waduh (menyatakan heran, kagum, terkejut), syukurlah (menyatakan lega dan senang), asyik (senang), eh (heran dan kaget), dan aduh (heran dan sakit) masing-masing 2 kali. Selain itu, kata seru lainnya yang ditemukan adalah kata seru, seperti, ayo, oh, oh ya, sih, wow, yuk, yah, halo. Akan tetapi, dalam buku BIPA, penjelasan tentang kata seru dan ekspresi dalam bahasa Indonesia belum ditemukan.

\section{Singkatan}

Tabel 7

Singkatan

\begin{tabular}{lc} 
Keterangan & Kosakata \\
\hline Singkatan & PR, PT, ATM, HP, PBB, RP, SD, SMP, SMA, WIB
\end{tabular}

Dalam bahasa Indonesia terdapat banyak sekali singkatan. Singkatan yang tidak dapat dihindari dan hampir digunakan setiap hari adalah singkatan kata handphone, HP, dalam konteks sehari-hari, PR dengan konteks pendidikan, SD, SMP, dan SMA untuk konteks sekolah, dan PT dengan konteks pekerjaan. Hal-hal yang telah dijelaskan di atas sebaiknya dibuat dalam catatan dalam bahan ajar sehingga pemelajar BIPA dapat memahami walaupun tidak diajarkan sebagai materi ajar. 


\begin{abstract}
Akhiran -nya
Temuan lain adalah kemunculan kata menggunakan akhiran -nya yang sangat banyak, seperti, baiknya, bahannya, budayanya, daftarnya, formulirnya, diskonnya, dosennya, baksonya, ayamnya, dan bantuannya. Pada pemelajar BIPA pemula, pengenalan -nya hanya sebatas persona ketiga, menyatakan kepunyaan. -nya adalah klitika varian pronominal persona ia dan dia dan pronominal benda yang menyatakan milik, pelaku, atau penerima. Akan tetapi, tidak dapat dimungkiri bahwa akhiran -nya yang muncul pada materi ajar pemula bukan hanya sebagai persona ketiga. Akiran -nya yang menyatakan arti hal yang telah dilakukan, sifat dan keadaan, petunjuk, dan makna lainnya. Semua makna tersebut dapat dipahami dari konteksnya. Dengan demikian, akhiran -nya yang bukan bermakna kepunyaan sebaiknya diminimalisasi penggunaanya.
\end{abstract}

\title{
Kosakata Berimbuhan
}

Berikut adalah bentuk kata berimbuhan yang diperoleh dari korpus data.

Tabel 8

Kosakata Berimbuhan

\begin{tabular}{ll}
\hline Imbuhan & Kosakata \\
\hline pe- & petugas, pelayan, pembeli, pedagang \\
\hline ber- & $\begin{array}{l}\text { bertanya, berangkat, bersama, berjalan, berlibur, berolahraga, berbicara, } \\
\text { berkacamata, bersaudara, berwisata, berbelanja, bernama, berumur }\end{array}$ \\
\hline pe-an & Pekerjaan \\
\hline men- & $\begin{array}{l}\text { melihat, membantu, memesan, merasa, membeli, menelepon, mengantar, } \\
\text { membayar, menikah, menunggu, menyewa, (awalan men- paling sering } \\
\text { muncul) }\end{array}$ \\
\hline men-kan & menanyakan, menjelaskan, menyenangkan, menggunakan \\
\hline -kan & kenalkan, sampaikan, bandingkan dengan kata sedangkan \\
\hline -an & makanan, retoran, liburan, ungkapan, pakaian, jurusan \\
\hline per-an & perkenalan, perpustakaan, penggunaan, pertigaan, percakapan, pelajaran, \\
& pemakaian \\
\hline ber-an & Berkenalan \\
\hline se-nya & sebaiknya, se-nya \\
biasanya, caranya, ongkonsnya (the), sepertinya, biayanya, bonnya, \\
menunya, minumnya, kembaliannya
\end{tabular}

Kata berimbuhan dalam bahasa Indoensia tidak dapat dihindari penggunaannya, begitu juga dalam buku BIPA pemula. Berdasarkan SKL, pemelajar BIPA 1-2, harus menguasai 
penggunaan kata berimbuhan ber- yang bermakna punya dan pakai, dengan tepat; imbuhan me- yang bermakna melakukan ativitas; dan imbuhan -an dengan makna hasil dari di-. Dengan demikian, imbuhan yang harus dikuasai adalah verba berimbuhan ber- dan meN, dalam bentuk sederhana belum dalam bentuk kompleks, seperti per-kan, dan meN-kan.

\section{PENUTUP}

HFW yang muncul pada tema-tema pembelajaran BIPA pemula level satu dan dua berbeda dengan HFW yang pernah dihasilkan berdasarkan kajian-kajian sebelumnya. Hal ini terjadi karena pilihan korpus data yang digunakan berbeda. HFW yang dibutuhkan, khususnya pemelajar BIPA pemula adalah kata yang berhubungan dengan konteks diri dan pemenuhan kebutuhan konkret sehari-hari dan rutin dengan cara sederhana. Sehingga kata pronomina (saya, aku, Anda, kamu), sapaan (Pak, Bu), tanya (apa, berapa), dan preposisi (di, ke, dari) menjadi kata yang cukup tinggi kemunculannya. Bentuk kata yang muncul dari data yang diperoleh sangat beragam. Kelas kata yang hadir beragam, bentuk nomina, verba, ajektiva, pronominal, partikel, numerilia, dan klitika. Selain itu, kata seru atau interjeksi yang muncul juga bermacam-macam sesuai dengan fungsi penyataannya, seperti menyatakan kagum, heran, terkejut, lega, senang, dan sakit.

Pengajar, perencana pengajaran, dan penulis materi ajar juga sebaiknya mempertimbangkan memasukkan singkatan dalam pengajaran atau bahan ajar pemula, khususnya yang biasa digunakan, seperti PR, ATM, HP, WIB. Dalam kehidupan sehari-hari singkatan tidak dapat diabaikan kehadirannya. Akan tetapi, dalam SKL tidak ada topik mengenai singkatan sebagai target yang harus dikuasai. Meskipun kehidupan berbahasa sehari-hari dipenuhi dengan singkatan yang sudah dianggap sebagai bagian dari kata. Hal lain yang perlu diperhatikan adalah bentuk -nya yang bukan persona ketiga yang cukup tinggi kemunculannya perlu dieliminasi dari bahan ajar pemula. Selain itu, bentuk berimbuhan untuk level yang lebih tinggi juga seharusnya tidak muncul, seperti meng-kan, pe-an, dan per-an.

\section{DAFTAR PUSTAKA}

Maharani, A. V. (2019). Pemerolehan Kosakata Bahasa Korea pada Pembelajar Dewasa Indonesia. Ranah: Jurnal Kajian Bahasa, 8(2), 255. https://doi.org/10.26499/rnh.v8i2.962

Purwiyanti, Y., Suwandi, S., \& Andayani, N. (2017). Strategi Komunikasi Pemelajar Bahasa Indonesia bagi Penutur Asing Asal Filipina. Ranah: Jurnal Kajian Bahasa, 6(2), 160. https://doi.org/10.26499/rnh.v6i2.448

Ramadan, S., \& Yeti Mulyati. (2020). Makna Kata dalam Bahasa Indonesia (Salah Kaprah dan Upaya Perbaikannya). Ranah: Jurnal Kajian Bahasa, 9, 90-105. https://doi.org/doi: https://doi.org/10.26499/rnh.v9i1.1036 
Bhinnety, M. (2015). Struktur dan Proses Memori. Buletin Psikologi, 16(2), 74-88. https://doi.org/10.22146/bpsi.7375

Corpora and Language Statistics. diakses pada tanggal 14 Juli 2020. https://cls.corpora.unileipzig.de/en/ind_mixed_2013/3.2.1_The\%20Most \%20Frequent $\% 2050 \% 20 \mathrm{Words} . \mathrm{html}$

Dang, T. N. Y., Webb, S., \& Averil Cohead. (2019). This is a repository copy of Evaluating lists of high-frequency words: Teachers' and learners' perspectives. White Rose Research Online URL for this paper: Version: Accepted Version Article: Dang, TNY orcid. org/0000-0002-31897776, Webb, S a. University of Leeds, 1-30. Retrieved from http://eprints.whiterose.ac.uk/154599/

Frost, R. L. A., Monaghan, P., \& Christiansen, M. H. (2019). Mark My Words: High Frequency Marker Words Impact Early Stages of Language Learning. Journal of Experimental Psychology: Learning Memory and Cognition, 45 (10), 1883-1898. https://doi.org/10.1037/xlm0000683

Jendrych, E. (2013). Developments in esp teaching. Studies in Logic, Grammar and Rhetoric, 34 (47), 43-58. https://doi.org/10.2478/slgr-2013-0022

Johns, J. L., \& Wilke, K. H. (2018). High frequency words: some ways to teach and help students pratice and learn them. Texas Journal of Literacy Education, 6 (1), 3-13. Retrieved from https://www.mendeley.com/viewer/?fileId=354e4718-bc11-5edb-42f7-a39 bc4db1f3a\&documentId=136393f0-fbe8-3298-aefa-ff72f5938f0d

KBBI, 2016. Kamus Besar Bahasa Indonesia (KBBI). Diakses dari https://kbbi.kemdikbud.go.id/

Laurance Anthony's Website. diakses pada tanggal 14 Juli 2020 https://www.laurenceanthony.net/software.html

Lightbown, P. M \& Spada, N. 2011. How Languages Are Learned. Oxford University Press

Muhadjir, dkk., 1996, Frekuensi Kosakata Bahasa Indonesia, Depok: Fakultas Satra Universitas Indonesia.

Nation, I. S. P. (2001). Learning Vocabulary in Another Language. Cambridge: Cambridge University Press. https://doi.org/10.1017/CBO9781139524759

PUEBI. 2015. Pedoman Umum Ejaan Bahasa Indonesia diakses dari https://puebi.readthedocs.io/en/latest/

Sánchez Gutiérrez, C. H., Serrano, M. P., \& García, P. R. (2019). The effects of word frequency and typographical enhancement on incidental vocabulary learning in reading. Journal of Spanish Language Teaching, 6 (1), 14-31. https://doi.org/10.1080/23247797.2019.1590000

Sereno, S. C., Hand, C. J., Shahid, A., Mackenzie, I. G., \& Leuthold, H. (2020). Early EEG correlates of word frequency and contextual predictability in reading. Language, Cognition and Neuroscience, 35 (5), 625-640. https://doi.org/10.1080/23273798.2019.1580753

University of Cambridge. (2011). Using the CEFR: Principles of Good Practice. Diakses dari https://www.cambridgeenglish.org/Images/126011-using-cefr-principles-of-good-practice.pdf 